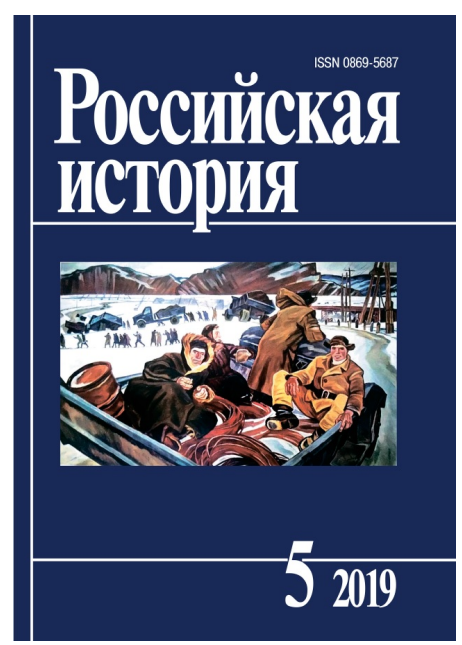

Российская история. 2013-2023

ISSN 0869--5687

URL - http://russian-history.ru

Все права защищены

Выпуск 5 Том . 2019

\title{
Peц. нa: T. Hasegawa. Crime and Punishment in the Russian revolution. Mob justice and Police in Petrograd. Camdridge (Mass.): The Belknap Press of Harvard University Press, 2017. 351 p.
}

\section{Калашников Виктор Валерьянович}

Санкт-Петербургский государственный электротехнический университет Российская Федерачия, Санкт-Петербург

\section{Николаев Андрей Борисович}

Российский государственный педагогический университет им. А.И. Гериена Российская Федераиия, Санкт-Петербург

\section{Аннотация}

Ключевые слова:

Дата публикации: 12.09.2019

Ссылка для цитирования:

Калашников В. В. , Николаев А. Б. Рец. на: Т. Hasegawa. Crime and Punishment in the Russian revolution. Mob justice and Police in Petrograd. Camdridge (Mass.): The Belknap Press of Harvard University Press, 2017. 351 p. // Российская история. 2019. - Выпуск 5 C. 231-238 . URL: https://russian-history.ru/s086956870006395-5-1/. DOI: $10.31857 / \mathrm{S} 086956870006395-5$

\footnotetext{
1 порно мамки

2 порно мамки

3 порно мамки
} 
5 порно мамки

6 порно мамки

7 порно мамки

8

порно мамки

порно мамки

10

порно мамки

11 порно мамки

12 порно мамки

13 порно мамки

14 порно мамки

15 порно мамки

16 порно мамки

17 порно мамки

18 порно мамки

19 порно мамки

20 порно мамки

21 порно мамки

22 порно мамки

23 порно мамки

24 порно мамки

25 порно мамки

26 порно мамки

27 порно мамки

Примечания:

порно мамки

порно мамки

порно мамки

порно мамки

порно мамки

порно мамки 


\section{Библиография:}

1. Hasegawa T. Crime and Police under the Soviet Regime, October 1917 - March 1918 // Революция 1917 года в России: новые подходы и взгляды. Сборник научных статей / Ред. и сост. А.Б. Николаев, Д.А. Бажанов, А.А. Иванов. СПб., 2015. С. $272-$ 298.

2. Hasegawa T. Crime and Punishment in the Russian revolution. Mob justice and Police in Petrograd. Cambridge (Mass.), 2017.

3. Hasegawa T. Crime, Police, and Samosudy in Petrograd in the Russian Revolution and Sociological Theories of Anomie // Journal of Modern Russian History and Historiography. 2016. Vol. 9. P. 275-296.

4. Hasegawa T. The February revolution: Petrograd, 1917. Seattle, 1981.

5. Hasegawa T. The February revolution: Petrograd, 1917. The End of the Tsarist Regime and the Birth of the Dual Power. Leaden, 2017.

6. Ведун. Разрушенные гнезда кокаинистов // Петроградский листок. 1917. 4 мая. «Новое время» сообщало, что Вольман был осуждён на десять месяцев тюремного 
заключения (За продажу кокаина // Новое время. 1917. 28 марта).

7. Ерещенко Д.Ю. Преступность в Петрограде в 1914-1917 гг. Дис. ... канд. ист. наук. СПб., 2003.

8. Меншуткин В. Временные суды в Петрограде // Журнал Министерства юстиции. 1917. № 4. С. 186.

9. Петров Ю.А. Российская революция 1917 года: власть, общество, культура // Вестник Российского фонда фундаментальных исследований. Гуманитарные и общественные науки. 2017. № 2. С. 17-18.

10. Пешехонов А.В. Первые недели (Из воспоминаний о революции) // На чужой стороне. Кн. 1. Берлин, 1923. С. 267.

11. Хасегава Ц. Государственность, общественность и классовость: преступление, полиция и государство во время Русской революции в Петрограде // Новый мир истории России. Форум японских и российских исследователей. К 60-летию профессора Вада Харуки. М., 2001. С. 218-246.

12. Хасегава Ц. Преступность и социальный кризис в Петрограде во время Русской революции: март-октябрь 1917 г. // Россия в 1917 году: новые подходы и взгляды. Вып. 3. СПб., 1994. С. 72-79. 


\section{T. Hasegawa. Crime and Punishment in the Russian revolution. Mob justice and Police in Petrograd. Camdridge (Mass.): The Belknap Press of Harvard University Press, 2017. 351 p.}

\section{Viktor Kalashnikov}

Saint Petersburg Electrotechnical University

Russian Federation, Saint-Petersburg

Andrey Nikolaev

Herzen State Pedagogical University of Russia

Russian Federation, Saint-Petersburg

Abstract

Keywords:

Date of publication: 12.09.2019

Citation link:

Kalashnikov V., Nikolaev A. T. Hasegawa. Crime and Punishment in the Russian revolution. Mob justice and Police in Petrograd. Camdridge (Mass.): The Belknap Press of Harvard University Press, 2017. 351 p. // Rossiiskaia istoriia. - 2019. - Issue 5 C. 231-238 . URL: https://russian-history.ru/s086956870006395-5-1/. DOI: $10.31857 / \mathrm{S} 086956870006395-5$

Код пользователя: 0; Дата выгрузки: 26.04.2023; URL - http://russian-history.ru/s086956870006395-5-1/ Bce права защищены. 